\title{
Capsule Commentary on Bowling et al., Prevalence of Activity Limitations and Association with Multimorbidity Among US Adults 50 to 64 Years Old
}

\author{
Katie Jordan, OTD, OTR/L \\ J Gen Intern Med 34(11):2583 \\ DOI: $10.1007 / \mathrm{s} 11606-019-05297-9$ \\ (c) Society of General Internal Medicine 2019
}

Chan Division of Occupational Science and Occupational Therapy, University of Southern California, Los Angeles, CA, USA.
$\mathrm{T}$ he majority of older adults report having multiple chronic conditions, which can result in disproportionate utilization of health care resources due to functional limitations and challenges with the management of chronic conditions. ${ }^{1}$ In this study, Bowling et al. found that adults 50-64 years of age often experience functional decline resulting in limitations in function (34\%), mobility (11.2\%), BADLs (14.6\%), and IADLs $(16.8 \%){ }^{2}$ In addition, there is a progressive association between the number of chronic conditions present and the existence of activity limitations. This thought-provoking study challenges clinicians to consider the correlation of activity limitation and multimorbidity, the temporality of that correlation, and the barriers to addressing this issue in a crowded primary care landscape.

Multimorbidity and activity limitations are serious health issues that negatively impact quality of life and the cost of health care. ${ }^{3}$ While the discovery of chronic conditions using an EMR may be more feasible than determining if functional limitations exist for this age group, caution regarding acceptance of this directionality is advised. Our health impacts our functional capacity, but what we do also impacts our health. The chronic conditions included in this study are sensitive to lifestyle-based, modifiable risk factors. Restrictions in daily activities due to physical, mental, or behavioral health challenges can impact habits and routines which in turn can significantly modify risk for the development of chronic conditions and/or related co-morbidities.

By addressing the correlation between chronic conditions and functional limitations in middle-aged adults, regardless of directionality, Bowling and colleagues bolster the argument for health promotion and prevention. If we can address these factors early, the impact of age-related health declines could be significantly mitigated. How though, do we pile on to overburdened primary care providers? One solution is to support a team-based approach. Comprehensive primary care models that include prevention and pre-habilitation, such as early occupational therapy services, have demonstrated improved clinical outcomes, better patient activation, and healthy aging that cost-effectively reduces the risk of age-related health declines. ${ }^{4}$ In fact, health systems with comprehensive, teambased primary care result in improved population health, lower costs, and increased provider satisfaction. ${ }^{5}$

Corresponding Author: Katie Jordan, OTD, OTR/L; Chan Division of Occupational Science and Occupational Therapy University of Southern California, Los Angeles, CA, USA (e-mail: mkjordan@med. usc.edu).

\section{Compliance with Ethical Standards:}

Conflict of Interest: The author declares that she does not have a conflict of interest.

\section{REFERENCES}

1. Leland NE, Fogelberg DJ, Halle AD, Mroz TM. Occupational therapy and management of multiple chronic conditions in the context of health care reform. Am J Occup Ther. 2017;71. https://doi.org/10.5014/ajot.2017. 711001

2. Bowling CB Deng L, Sakhuja S, Morey MC, Jaeger BC, Muntner $\mathbf{P}$ Prevalence of activity limitations and association with multimorbidity among US adults 50 to 64 years old. J Gen Intern Med. 2019; https:// doi.org/10.1007/s11606-019-05244-8.

3. McPhail SM. Multimorbidity in chronic disease: impact on health care resources and costs. Risk Manag Healthcare Policy. 2016;9:143-156. https://doi.org/10.2147/RMHP.S97248.

4. Clark F, Azen SP, Zemke R, Jackson J, Carlson M, Mandel D, ... Lipson L. Occupational therapy for independent-living older adults. A randomized controlled trial. JAMA. 1997;278:1321-1326. https://doi.org/10.1001/ jama.1997.03550160041036

5. Weidner AKH, Phillips RL Jr, Fang B, Peterson LE. Burnout and scope of practice in new family physicians. Ann Fam Med. 2018;16:200-205. https://doi.org/10.1370/afm.2221

Publisher's Note Springer Nature remains neutral with regard to jurisdictional claims in published maps and institutional affiliations. 